\title{
LA REALIDAD VIRTUAL EN TELEVISIÓN: EL PASO DEL ÁTOMO AL BIT
}

\author{
Esteban Galán Cubillo \\ (Universidad Jaume I de Castellón) ${ }^{1}$ \\ egalan@com.uji.es
}

\begin{abstract}
Resumen: Desde los comienzos de la televisión, los actores se posicionaban en el estudio ante un escenario simple. La función del escenario era crear un espacio, un tiempo y una atmósfera. Sin embargo, muy pronto se necesitó ofrecer al espectador una impresión de espacio que rompiera con el set tradicional. En este contexto se enmarca el fenómeno primero del croma-key y después de la escenografía virtual, que surge como una aplicación de la realidad virtual en el campo televisivo. El uso de esta tecnología introduce novedades significativas en las estructuras representativas del discurso televisivo. La puesta en escena se desmaterializa, abandonando su referente real en favor de la imagen de síntesis, fruto del proceso de incrustación digital entre la señal de cámara y el entorno virtual. El escenario virtual sustituye el espacio televisivo real por un espacio televisivo que produce un efecto de realidad.
\end{abstract}

Palabras clave: Realidad virtual, escenografía virtual, televisión.

Abstract: Since the beginning of television, the actors were placed in the studio within a simple scenario. The scenario functions were to build a space, a time and an atmosphere. Nevertheless, it was soon necessary to present for the audience a view of space breaking with the traditional set. In this context it arises the croma-key and the virtual studio in the television field. The use of this technology introduces remarkable news in the representative frameworks of television plot. The staging dematerialises, leaving the real referent in favour of synthesis image, as a result of the digital inlay process between camera signal and virtual setting. The virtual scenario replaces the real television space with a television space producing a reality effect.

Keywords: Virtual reality, virtual set, television

\section{DE LA PARADOJA DE UNA REALIDAD QUE ES VIRTUAL}

A la realidad virtual, al ser una disciplina todavía reciente, se le han aplicado múltiples definiciones y nomenclaturas conforme su uso y sus aplicaciones se han ido modificando y ampliando. Al intentar delimitar conceptualmente el fenómeno aparece una gran diversidad de términos, a saber: realidad virtual, entorno virtual, realidad artificial, entorno artificial, entorno generado por ordenador,

${ }^{1}$ El Grupo de Investigación I.T.A.C.A.-UJI (Investigación en Tecnologías Aplicadas a la Comunicación Audiovisual de la Universitat Jaume I), dirigido por Javier Marzal, cuenta con financiación de BANCAJAUJI y del Ministerio de Ciencia y Tecnología. 
entorno artificial, inmersión espacial, ciberespacio, mundo virtual, tele-presencia ${ }^{2}$ etc. En función de la terminología elegida para describir el fenómeno, se está privilegiando unos u a otros aspectos de la tecnología. Esta circunstancia la explicita Cruz-Neira (1993: 1) cuando distingue entre mundo y entorno:

El término más adecuado sería el de entorno virtual que alude además al sentido del tacto, el olfato y el oído. Aunque el entorno virtual (VE) forma parte del acrónimo CAVE, usaremos las iniciales VR debido a su uso predominante.

Para Cruz-Neira es adecuada la utilización del término realidad virtual por ser el término de uso más extendido en la comunidad científica. Realidad y virtual son dos conceptos, en teoría antagónicos, pero que juntos dan naturaleza de existencia al fenómeno objeto de estudio. Al acudir a la definición del término virtual, se encuentra que la palabra virtual proviene del término latino virtus que significa fuerza y virtud, como apunta el Diccionario de la Real Academia de la Lengua: "Que tiene virtud para producir un efecto, aunque no lo produce de presente. Frecuentemente en oposición a efectivo o real”.

Por tanto, aunque lo virtual es lo opuesto a lo real, no debe entenderse desde un punto de vista peyorativo como sinónimo de falso. Lo virtual es aquello capaz de producir un efecto aunque no lo haga de una forma presente. Lo virtual nos traslada a otros mundos o entornos que no son los físicamente inmediatos.

La Real Academia también contempla la acepción realidad virtual en su conjunto y la define como: "Representación de escenas o imágenes de objetos producida por un sistema informático, que da la sensación de su existencia real".

Esta definición resulta en exceso amplia ya que dentro podría abarcar campos como la infografía o el multimedia que no están dentro de la realidad virtual. Es importante acotar el término para diferenciar la RV de lo que puedan significar otros sistemas informáticos. Un sistema de realidad virtual se distingue de otro tipo de aplicaciones multimedia o infográficas en cuatro aspectos:

1. Inmersión: El usuario tienen la sensación de encontrarse dentro de un mundo tridimensional.

2. Punto de referencia: Existe un punto que permite determinar la ubicación del usuario en el entorno virtual.

3. Navegación: El usuario puede cambiar su punto de referencia.

4. Interacción: El usuario puede interaccionar con el entorno virtual, de forma que sus acciones tienen consecuencias en dicho entorno. El espacio virtual surge de la interacción entre el ser humano y la computadora. Por

\footnotetext{
${ }^{2}$ Los equivalentes en inglés son: virtual reality, virtual environment, artificial reality, computer generated environment, computer simulated environment, synthetic environment, spatial inmersion, cyberspace, virtual worlds, virtual presence.
} 
tanto, aunque habitualmente se hable de que el ser humano interacciona con el espacio virtual, es así, pero de un modo figurado. En un sentido estricto, el ser humano interacciona con la computadora, se comunica con ella a través de unos dispositivos de interacción y es la computadora la que transmite esos datos al entorno virtual. Por tanto, el entorno virtual es el resultado de un devenir, entendido como una suma, entre el ser humano y la máquina.

\section{HACIA UNA DEFINICIÓN DE LA REALIDAD VIRTUAL}

En el apartado anterior se han constado dos hechos. Etimológicamente el propio concepto de realidad virtual supone una paradoja ya que virtual parece un significado opuesto a la realidad. La realidad virtual es el producto de la comunicación entre el ser humano y la máquina.

Pérez Huertas (1998: 3) aborda estas dos cuestiones en la definición que ofrece de realidad virtual:

Realidad virtual: se llama así al tipo de representación que mediante distintos sistemas computerizados y los periféricos apropiados permite situar al usuario en una especie de mundo electrónico de tres dimensiones que tiene la virtud de producir un efecto de realidad.

Pérez Huertas resuelve y aclara la paradoja conceptual que implica el término de RV cuando afirma que "tiene la virtud de producir un efecto de realidad". Es importante recordar que uno de los significados etimológicos de la palabra virtual es virtud y esta virtud (como comenta Pérez Huertas) es la de producir un efecto de realidad. El usuario de un sistema de realidad virtual es consciente de que no está ante la realidad efectiva, pero es capaz de percibir la sensación de estar ante ella. El entorno virtual, por tanto, no es una realidad en sí misma sino que produce lo que Pérez Huertas denomina "un efecto de realidad".

Este efecto de realidad se consigue a través de la simulación de los mecanismos sensoriales del hombre a través del software. El sistema de realidad virtual no construye una realidad paralela sino que construye un entorno en el que el usuario experimenta una sensación de inmersión y una capacidad de interacción con ese entorno de la forma más similar posible a como sería en el mundo real. Por tanto, el entorno que ofrece la realidad virtual, sólo existe dentro del ordenador. De esta forma, cuando se dice que el usuario interacciona con el entorno virtual, en el fondo se está diciendo que interacciona con el propio ordenador.

Por otro parte, para que el usuario obtenga la sensación de inmersión dentro de ese mundo, es necesario que los sentidos reciban información, cuanto más rica mejor, al mismo tiempo que interaccionan con el entorno. Esta recepción de información del entorno, es lo que va a dar la ilusión de autenticidad. En palabras de Muñoz (1993: 93) la realidad virtual es: "La simulación completa de un ambiente, con sus objetos, sonidos y hasta climas [...]". En el mismo sentido 
se coloca la definición que ofrece Burdea (1994: 236): "es un interfaz de usuario innovadora que incluye simulación en tiempo real e interacciones a través de una diversidad de canales sensoriales. Estas modalidades sensoriales son visual, auditiva, táctil, olfativa, gustativa, etc.".

Por tanto, el ordenador lanza los input a los sentidos del ser humano, trata de saturarlos a través de los estímulos y es la recepción de estos estímulos lo que le hace reconstruir un ambiente en donde sólo hay un flujo de bits. Cuando se entra en un entorno virtual, se está, por tanto, suplantando el átomo por el bit.

El recorrido realizado hasta el momento deja clara la existencia de muchas definiciones para explicar el fenómeno de la realidad virtual. Ante este panorama, el objetivo es establecer unos requisitos que deba cumplir cualquier sistema o modalidad para ser considerado como realidad virtual. En este sentido Gustavo Salvador (en Galán, 2007: 553-570) afirma que:

la realidad virtual tiene muchas definiciones. Normalmente se define a través de conceptos. Uno de los más utilizados es el de las tres íes. Imaginación, interacción, inmersión. El que mejor define la realidad virtual dentro de los tres conceptos es el de inmersión.

Por tanto, Salvador propone definir los sistemas de realidad virtual a través de diferentes conceptos: inmersión, interacción e imaginación.

La inmersión, que Gustavo Salvador destaca de entre las tres características, consiste en la capacidad del usuario para perder el contacto con la realidad al percibir únicamente estímulos del mundo virtual. Un ejemplo clásico de este tipo de inmersión se encuentra en los visiocascos que aíslan al usuario de los estímulos de la realidad inmediata. Sin embargo, para que un sistema de realidad virtual sea considerado como tal, el grado de inmersión no tiene por qué ser absoluto. El grado de inmersión de un sistema va a depender fundamentalmente de dos factores: del grado de aislamiento del espacio sensitivo exterior que tenga el sistema y de la cantidad de estímulos que ofrezca al usuario el entorno virtual. Así, Román Gubern (2000: 201) define la RV inmersiva del siguiente modo:

La RV inmersiva constituye un sistema informático que genera entornos sintéticos en tiempo real, que son ilusorios, pues se trata de una realidad perceptiva envolvente sin soporte objetivo.

Otro concepto fundamental para valorar un sistema de RV es la interacción. A través de la interacción, el usuario se relaciona con el mundo virtual en tiempo real. Dorta (1999: 177) define lo que se considera como tiempo real a la hora de valorar un sistema:

El tiempo real ocurre cuando las respuestas del sistema debido a la interacción del usuario llegan de una manera tan rápida e instantánea, que tenemos la impresión que ocurren en tiempo normal.

El tiempo real, por tanto, expresa el hecho de que la respuesta que se produce en el mundo virtual a una acción en el mundo real, parece ser simultánea. 
Por último queda nombrar el concepto de imaginación que tiene una doble vertiente:

1. El usuario del sistema percibe cosas que en realidad no existen. A través de una simulación, el usuario construye un entorno virtual.

2. El desarrollador de la aplicación utiliza la tecnología disponible para idear un entorno lo más inmersivo e interactivo posible. Este entorno no tiene por qué imitar a la realidad conocida. Puede crear mundos imaginarios donde se desarrollen actividades impensables en el mundo real. El límite creativo de esta tecnología reside en la imaginación del creador ${ }^{3}$.

Para completar la definición del término de realidad virtual, junto a estos tres conceptos, es necesario incorporar la aportación de Carolina Cruz-Neira (1993: 1):

Un sistema de realidad virtual es aquel capaz de trackear el punto de vista a tiempo real con un gran ángulo de visión, un control interactivo y una visión estereoscópica.

En realidad virtual se trackea (se rastrea o se lleva a cabo un seguimiento) el punto de vista del usuario ${ }^{4}$. Por tanto, los dos requisitos técnicos que operan en una aplicación de realidad virtual son: el tiempo real que permite la interacción y el tracking o seguimiento del punto de vista que posibilita la inmersión del usuario.

Por tanto, la definición de realidad virtual se compone de la unión entre las tres "íes": inmersión, interacción e imaginación; combinados con la idea del tracking del punto de vista del usuario en tiempo real.

\footnotetext{
${ }^{3}$ En la praxis profesional se elude esta circunstancia achacando la falta de creatividad a elementos como la ausencia de tiempo o la limitación tecnológica.

${ }^{4}$ El término tracker puede ser traducido como seguimiento o rastreo.
} 
Figura 1. Definición de RV.

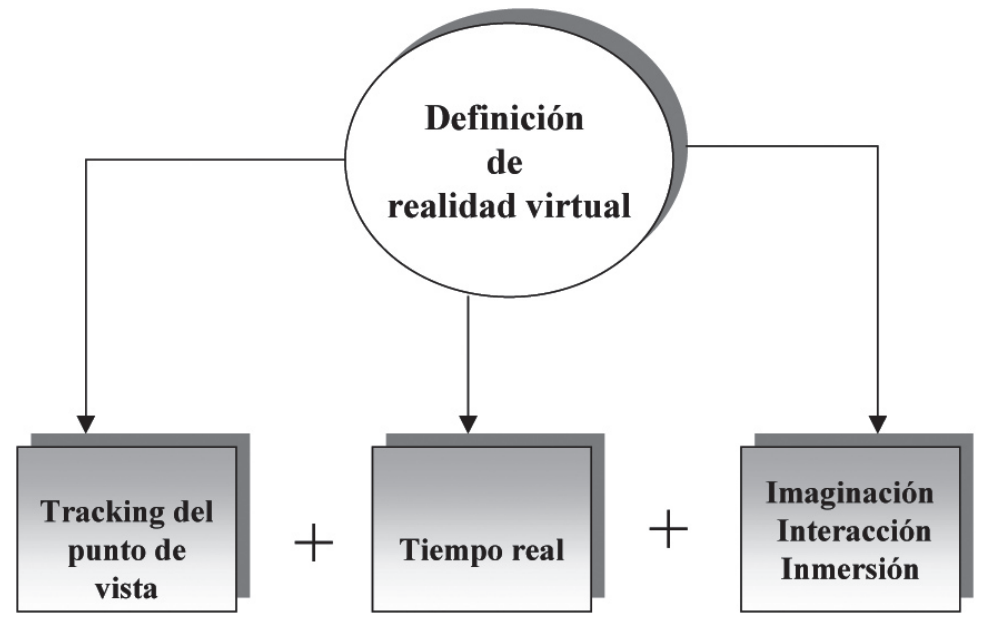

Fuente: Elaboración propia.

\section{APLICACIONES DE LA REALIDAD VIRTUAL}

\subsection{La realidad aumentada}

Ilustración 1. Visualización de una imagen típica de realidad aumentada

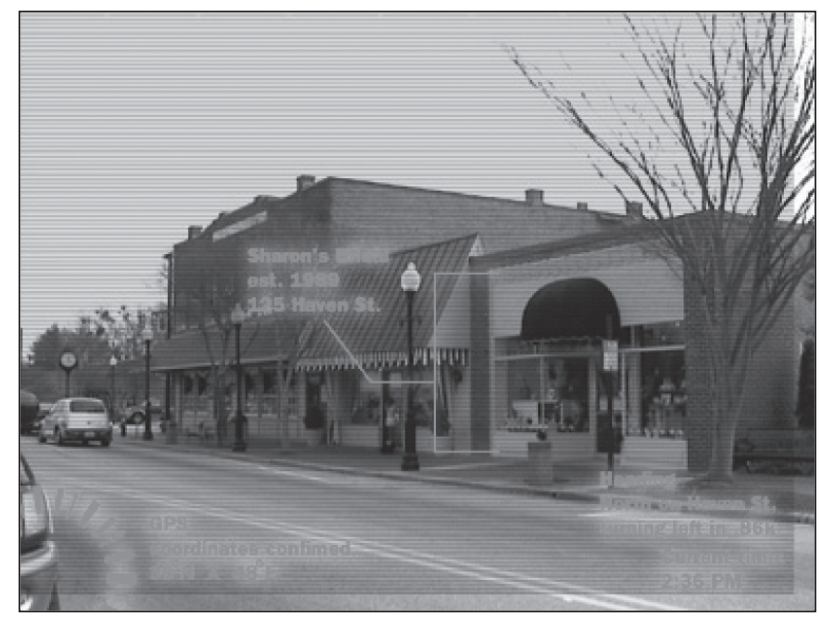

Fuente: http://computer.howstuffworks.com/augmented-reality.htm 
La realidad aumentada es una aplicación específica dentro de la realidad virtual. Javier Montesa (en Galán, 2005: 228-229) explica en qué consiste:

La realidad aumentada superpone sobre la imagen real, imagen virtual. Un caso prototípico lo podemos encontrar en los aviones. Los aviones tienen una pantalla semitransparente.

El piloto ve la realidad a través de esa pantalla pero también ve cosas superpuestas a la realidad. Aumenta esa realidad con datos.

La realidad aumentada, por tanto, superpone imagen virtual sobre la imagen real. La realidad aumentada surge para contrarrestar los problemas de cansancio ocular y mareos que producen algunos sistemas inmersivos de RV. En las aplicaciones de realidad aumentada el usuario no pierde el contacto con la realidad. El mundo virtual se superpone al mundo físico, sin reemplazarlo. El usuario ve una imagen compuesta por las imágenes generadas por ordenador y las escenas reales. Esta mixtura entre ambas realidades ha motivado que en ocasiones a la realidad aumentada también se le denomine realidad mixta.

Se puede distinguir entre dos tipos de realidad aumentada: realidad aumentada see-through y realidad aumentada video-see through.

Ilustración 2 y 3. Dispositivo HMD.
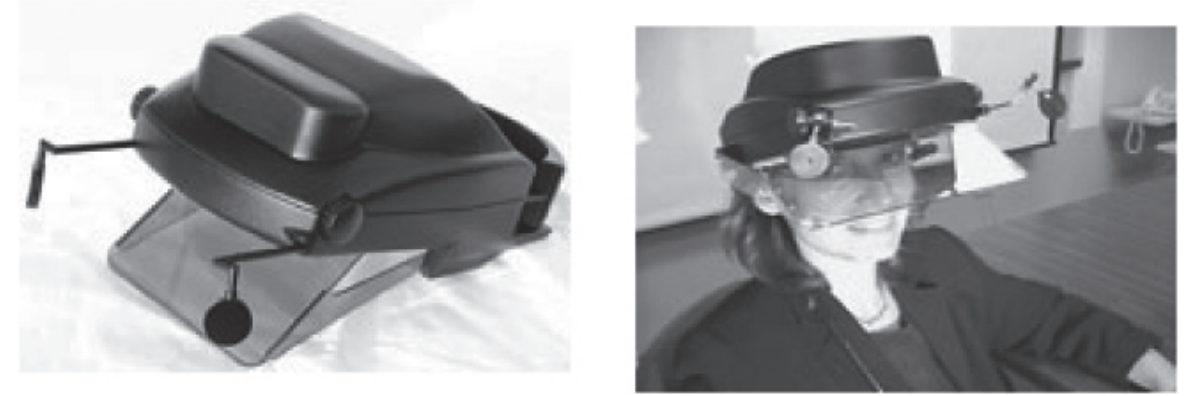

Fuente: http://www.opticsreport.com/content/article.php?article_id=1003\&page=2

Este dispositivo de HMD nos permite combinar la visión real con datos adicionales proyectados gráficamente sobre la imagen. Es el tipo de realidad aumentada más conocido y su funcionamiento coincide con el que habitualmente se emplea al hablar de realidad aumentada en un sentido genérico. García Alvarado (2001: 44) define la realidad aumentada see-through del siguiente modo:

También los dispositivos recientes proyectan las imágenes con espejos desde la parte superior, con lo cual se puede retirar o difuminar la cubierta frontal y tener una visión completa de la situación real con la imagen virtual sobrepuesta (denominado see-through: ver a través). 
En la realidad aumentada see-through, por tanto, el usuario lleva dos cristales líquidos semitransparentes, a través de los cuales percibe la realidad exterior con la imagen del ordenador superpuesta.

Ilustración 4. Dispositivo de realidad aumentada video-see-through.

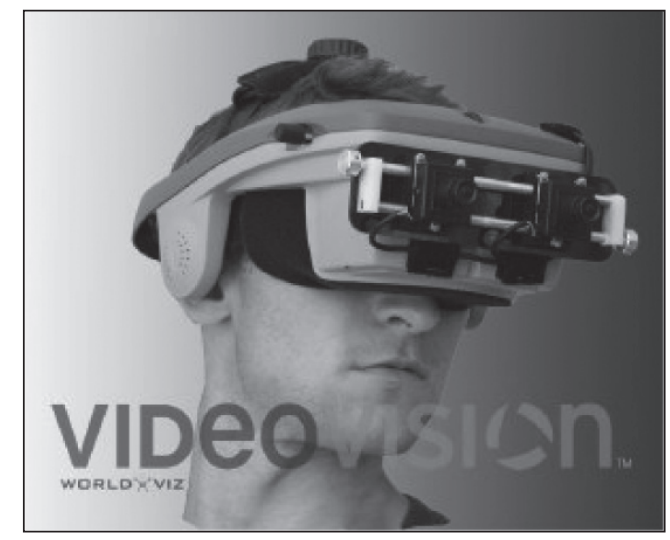

Fuente: http://www.nvisinc.com/vseethru.php

En la realidad aumentada video-see-through se pierde el contacto directo con la realidad exterior. El contacto con nuestra realidad inmediata existe, pero se produce a través de una imagen de vídeo. Javier Montesa (en Galán, 2005: 228229) describe la realidad aumentada video-see-through como sigue:

También está la video-see-through que consiste en unos cascos con los cristales líquidos en los que yo veo las imágenes pero no puedo ver a través de ellos. Tengo unas cámaras en el propio casco. Mis dos cámaras capturan imagen real y me la muestran y encima de esa imagen de vídeo yo puedo superponer cosas. Es muy parecido por tanto, a la televisión.

Las aplicaciones de la realidad aumentada video-see-through son múltiples. Una de las aplicaciones que más éxito ha tenido se ha producido en el ámbito televisivo con los sistemas de escenografía virtual.

\subsection{La aparición de la escenografía virtual}

Aunque los primeros experimentos de trabajo con croma-key se remontan en cine a la década de los 50 , no es hasta mediados de la década de los 90 cuando aparece la escenografía virtual en televisión. En 1994, Ultimatte en colaboración con IMP presenta en el NAB el primer escenario virtual en tiempo real de la historia. Los tres condicionantes que permitieron el surgimiento de esta tecnología son de orden estético, económico y tecnológico. 
En el croma-key tradicional los actores se graban sobre un fondo azul o verde. La señal de cámara se mezcla en un croma-keyer con el escenario virtual. Así es el modo en que tradicionalmente se ha dado la información meteorológica. Sin embargo, esto tiene un inconveniente técnico y es que el plano debe ser fijo, porque no existe una correlación de movimiento entre el foreground o señal de cámara y el movimiento del background. Cualquier movimiento de la cámara -panorámica horizontal, vertical o zoom- produciría un efecto indeseable ya que el background se mantiene estático mientras que la señal de cámara cambia. La aparición del escenario virtual se debe entender, por tanto, enclavada dentro de las investigaciones realizadas para la superación de este inconveniente.

La escenografía virtual es fruto de una intensa investigación tecnológica. Esta investigación tecnológica requiere una gran inversión económica de muchas empresas e instituciones, de tal forma, que se puede asegurar que sin este esfuerzo económico hubiera sido imposible la aparición de esta tecnología. Por tanto, y siguiendo a Rotthaler (1996: 2) no se puede separar el nacimiento y las características que tiene la escenografía virtual del factor económico que la hizo viable. Máxime cuando en un alto número de casos la decisión de poner o no en marcha un sistema de escenografía virtual depende de su rentabilidad económica.

Cuadro 1. Condicionante económico de RV.

FINALES DE LOS 80 Y PRINCIPIOS DE LOS 90

AUMENTO COMPETITIVIDAD

FRAGMENTACIÓN MERCADO BROADCAST

REDUCCIÓN DE INGRESOS

NECESIDAD DE REDUCIR COSTES

APUESTA POR OTRAS FORMAS DE PRODUCIR PROGRAMAS POR EJEMPLO LA ESCENOGRAFÍA VIRTUAL

Fuente: Elaboración propia. 
A finales de los 80 y principios de los 90 el sector de la comunicación vivió dos fenómenos que motivaron la necesidad de reducir los costes: el aumento de la competitividad y la fragmentación del mercado broadcast exigía producir programas de televisión en un menor tiempo y coste. Por tanto, en el mercado televisivo existía una gran receptividad hacia aquellos avances que permitieran conseguir una reducción del coste y un aumento del volumen de producción.

El uso de métodos de producción más económicos no es una opción sino una necesidad imperiosa para que determinados productos puedan mantener su viabilidad: "La nueva televisión se ha planteado desde la especialización de contenidos, las televisiones en abierto con sus estructuras y contenidos variados ofrecen un producto que para muchos está llamado a desaparecer" (Millán, 2005: 85). Las cadenas o empresas productoras que no optan por sistemas de producción y gestión de los contenidos más eficientes, están abocadas a su desaparición. Algunos autores como Fandiño (2001: 35) ven en esta reducción de costes un incentivo a la creatividad. La reducción del coste del equipamiento técnico permite el acceso a los medios de producción a los creadores con talento, sin necesidad de contar con un gran respaldo económico, como sucedía hasta la década de los 90.

La aplicación práctica de la escenografía virtual a la televisión no hubiera sido posible sin la existencia de un sustrato técnico suficiente para resolver los problemas que la empresa planteaba. Según Rotthaler (1996: 2) los dos factores que han contribuido a la puesta en marcha de la escenografía virtual desde un punto de vista técnico han sido la digitalización del equipo de producción y el uso creciente de las tecnologías de la información en las empresas de broadcast. Gibbs (1998: 21-22) incide en la importancia del proceso de digitalización ya que muchos de los procesos que requiere la existencia de la escenografía virtual son en sí mismos digitales. Trabajar en un entorno digital elimina los inconvenientes que tiene realizar conversiones, simplificando así el proceso de trabajo.

\subsection{La escenografía virtual: una aplicación de la RV}

La escenografía virtual es una aplicación de una forma muy particular de la realidad virtual como es la realidad aumentada. Existen, como se ha visto en el anterior apartado, dos tipos de realidad aumentada como son la realidad aumentada see-through y la realidad aumentada video-see-through. La televisión es una realidad aumentada video-see-through aunque realiza el proceso inverso ya que mientras que en la realidad aumentada video-see-through se superpone imagen virtual sobre la imagen real, en la televisión se opera el proceso inverso superponiendo imagen real sobre el entorno virtual. 
Figura 2. Escenografía virtual y RV.

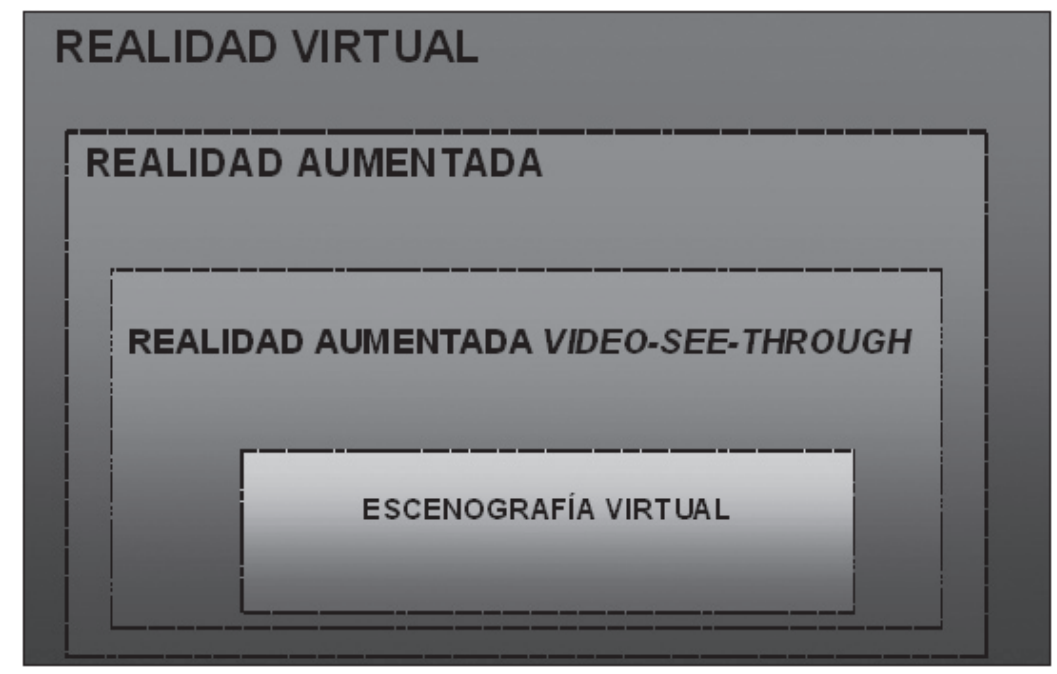

Fuente: Elaboración propia.

Por tanto, aunque entre los profesionales del medio televisivo todavía resulta común el empleo del término realidad virtual para referirse a un sistema de escenografía virtual, siguiendo a Pareja (1998: 5) lo correcto es hablar de escenografía virtual ya que la realidad virtual es un término más amplio y que está más conectado al mundo multimedia y a la simulación por ordenador.

Por otra parte, la escenografía nunca ha pretendido ser real. La escenografía crea un ambiente, un espacio sin la necesidad de tener que imitar a la realidad. Moshkovitz (2000: 6) defiende el término de realidad virtual como esencialmente correcto aunque lo descarta porque habitualmente se utiliza para otros campos como los videojuegos o los simuladores. El término escenografía virtual parece, pues, más apropiado, por ser específico de las aplicaciones televisivas.

Para definir la escenografía virtual es necesario delimitar el fenómeno y considerar los requisitos que debe cumplir cualquier sistema de escenografía virtual.

Los dos elementos clave por orden son: -la acción debe estar incorporada dentro de la imagen del background, -la imagen del background debe coincidir con la acción del foreground en tiempo real. Simple! Desafortunadamente no. El primer elemento requiere el uso normalmente del croma-key, mientras que el segundo necesita un sistema de tracking en tiempo real conectado a la cámara y que envíe la información al generador del background (Popkin, 1997:19). 
Para Popkin, el set virtual implica una ausencia de un escenario físico que es sustituido por un decorado generado por ordenador cumpliendo dos requisitos: la acción debe incorporarse dentro de la imagen del entorno virtual -a través del croma-key- y el entorno virtual debe actualizarse a tiempo real a la acción de la señal de cámara a través del tracking.

La escenografía virtual, por tanto, es el resultado de la incrustación entre el foreground que es la señal de cámara y el background que es un entorno virtual generado por ordenador. El entorno virtual se actualiza a tiempo real para adaptarse a los cambios de la señal de cámara. El resultado ante el telespectador es una imagen uniforme.

De esta definición se infiere que el uso de escenarios virtuales en televisión introduce modificaciones en el trabajo de puesta en escena en una producción televisiva. El espacio construido en el plató, la disposición física de elementos que se ubica ante las cámaras ya no coincide con el espacio que aparece en el discurso narrativo que llega el televidente.

El plató ha perdido su papel hegemónico como fuente única configuradora de la puesta en escena, y se ha convertido en un elemento más del proceso. Los dos nuevos elementos con los que comparte su protagonismo son: el proceso de integración y el escenario virtual generado en tiempo real. Esta pérdida de peso del decorado físico, en favor de procesos digitales de tratamiento de la información, desmaterializa el discurso televisivo.

La puesta en escena televisiva ha perdido su corporeidad intrínseca y camina hacia un espacio virtual, donde el átomo ha sido sustituido por el bit. En este espacio escénico la televisión alcanza una identidad propia, liberada ya de las ataduras dramatúrgicas, cinematográficas o radiofónicas que han lastrado durante casi cinco décadas su discurso.

La televisión, con el uso de escenarios virtuales, por tanto, encuentra su especificidad en el bit, que se convierte en el componente esencial de los equipos de producción y de la puesta en escena televisiva. Un bit que, pese a sus múltiples virtudes, resulta tal vez poco aprehensible, como lo es el parpadeo que produce esa televisión encendida en un salón vacío en mitad de la noche.

\section{LA ESCENOGRAFÍA VIRTUAL HOY}

En la actualidad, a nivel tecnológico, lo fundamental es la seguridad y la fiabilidad en el uso de los sistemas gráficos en tiempo real. Las plataformas de gráficos 3D centran sus esfuerzos en crear entornos de trabajo más robustos, fiables e intuitivos para el usuario. La implementación de nuevas soluciones creativas es, hoy día, más fruto del anhelo de los programadores que de una demanda real del mercado. 
Sin embargo, el abaratamiento de los sistemas ha provocado que los estudios de escenografía virtual dejen de ser coto exclusivo de las grandes cadenas de televisión para llegar también a manos de productoras independientes, con unos condicionantes más creativos. Esta transformación debe estimular la exploración de las nuevas posibilidades que ofrece la tecnología.

Para que estas tendencias sean una realidad, es fundamental contemplar la incorporación al mercado laboral de las nuevas generaciones de profesionales, más familiarizadas con el diseño 3D y los motores gráficos a tiempo real. Estos nuevos profesionales, demandan la implementación de sistemas, que consoliden el proceso de fusión que ya se ha iniciado entre las tecnologías de escenografía virtual y escenografía real, en un mismo estudio.

Dentro de estas investigaciones es interesante apuntar la importancia que, sin duda, puede tener la introducción de los sistemas de key de profundidad, en los que la llave se realiza a través del cálculo de la distancia que existe entre el objeto y la cámara, y por tanto, desaparece la necesidad del croma de color con la cantidad de problemas y limitaciones que lleva asociado. Otro hito clave es el de la consolidación y generalización en el uso de sistemas de tracking de objetos, que permitan establecer métodos de interacción con el entorno virtual que ofrezcan nuevas posibilidades creativas.

\section{REFERENCIAS BIBLIOGRÁFICAS}

BURDEA, G. (1995): Tecnologías de la realidad virtual. Barcelona: Paidós Hipermedia.

CRUZ-NEIRA, C.; SANDIN, D. J.; y DEFANTI, T. A. Surround-Screen Projection-Based Virtual Reality: The Design and Implementation of the CAVE. En Siggraph, 1993. International Conference on Computer Graphics and Interactive Techniques 1993. Los Ángeles.

DORTA, T. V. (1999): La realidad virtual dibujada como una nueva manera de hacer computación. En Primera Conferencia Venezolana sobre aplicación de computadoras en arquitectura. Caracas: FAU-UCV.

FANDIÑO, X.: "De Analogia a digitalia", Revista Latina de Comunicación Social, n 6 (2001), pp. 35-50.

FUKUI, K.; HAYASHI, M.; YAMANOUCHI, Y. (1996): Virtual studio system for tv program production. En IEEE Multimedia.

GALÁN, E.; DE SALAS, Ma Isabel (dir.) (2005): Análisis del funcionamiento técnico de la escenografía virtual en Televisión Valenciana. Valencia: UCH-CEU.

- (2007): El uso de escenografía virtual en la realización de un programa de televisión: desarrollo de un modelo ad hoc. Valencia: UCH-CEU.

GALÁN, E. (2008): Televisión en virtual. Madrid: IORTV.

- "Escenografía virtual en TV. Análisis del uso de escenografía virtual en la realización de un programa de televisión", Revista Latina de Comunicación Social, nº 63 (2008), pp.: 31-42. 
- "El trabajo del presentador de televisión en un escenario virtual", Revista Latina de Comunicación Social, nº 64 (2009), pp. 143-150.

GARCÍA, F. (1998): Realidad virtual y mundos posibles. En PABLOS PONS, J. de; y JIMÉNEZ SEGURA, J. J. (1998): Nuevas Tecnologías. Comunicación Audiovisual y Educación. Barcelona, Cedecs.

GARCÍA ALVARADO, R.; PARRA, J. C.; SANTELICES, I. (2001): Introducción Práctica a la realidad virtual. Concepción: Bio-Bio.

GIBBS, S. (et al.) (1998): "Virtual Studios: An Overview”. En IEEE Multimedia.

GUBERN, R. (1996): Del bisonte a la realidad virtual. Madrid: Anagrama.

- (2000): El eros electrónico. Madrid: Taurus.

LÓPEZ SILVESTRE, F. (2004): El paisaje virtual. El cine de Hollywood y el neobarroco digital. Madrid: Biblioteca Nueva.

MILLÁN, T.: "La televisión digital y sus repercusiones comunicativas: de públicos a usuarios", Ámbitos, no 13-14 (2005), pp. 79-89.

MORENO, I. (2002): Musas y nuevas tecnología. El relato hipermedia. Barcelona: Paidós.

MOSHKOVITZ, M. (2000): The Virtual Studio. Boston: Focal Press.

MUÑOZ, J. J. (1993): Expresión artística y audiovisual (de los primeros signos a la realidad virtual). Salamanca: Amarú.

PAREJA E. (1998): Escenografía virtual. Madrid: IORTV.

- (2005): Tecnología actual de televisión. Madrid: IORTV.

PÉREZ HUERTAS, F. J. (1998): Introducción a la multimedia: realización y producción de programas. Madrid: IORTV.

POMI, A.; SLUSALLEK, P.: "Interactive Ray Tracing for Virtual TV Studio Applications", Journal of Virtual Reality and Broadcasting, $\mathrm{n}^{\circ} 1$ (2005).

POPKIN, D.: "Virtual studios - the BBC's experience", EBU Technical Review (1997).

VIDAL ZANÓN, E. (2001): Visiocascos y tarjetas estereoscópicas. Valencia: UPV.

YAMANOUCHI, Y.; MITSUMINE, H.; FUKAYA, T.; y HAYASHI, M.: "Texture acquisition by a robot-arm camera -creation of an image-based virtual studio for dolly shots", NHK Laboratories Note, $\mathrm{n}^{\circ} 488$ (2004).

\section{Breve semblanza biográfica del autor}

Esteban Galán Cubillo, nacido en 1978 en Valencia, cuenta con un currículum académico en el que destaca el Premio Nacional 2003 y el Premio Extraordinario de Licenciatura 2002. Es Doctor en Comunicación Audiovisual por la Universidad Cardenal Herrera-CEU de Valencia y Profesor Asociado en la Universidat Jaume I de Castellón, con docencia en asignaturas de televisión, grafismo y realización televisiva. Forma parte del Grupo de Investigación 160 en Tecnologías aplicadas a la Comunicación Audiovisual - ITACA. Cuenta con publicaciones con el Instituto Oficial de Radio Televisión Española 
(IORTV) y con artículos en revistas indexadas y comunicaciones en Congresos. El autor compatibiliza su faceta académica con la profesional en las tareas de postproducción en el programa "Cor de Festa" que emite la televisión autonómica valenciana Canal 9 y que produce en colaboración con Malvarrosa Media.

(Recibido el 20-11-2009, aceptado el 02-02-2010) 
